\title{
Reintroduction of beavers Castor fiber may improve habitat quality for vespertilionid bats foraging in small river valleys
}

\author{
Mateusz Ciechanowski • Weronika Kubic • \\ Aleksandra Rynkiewicz • Adrian Zwolicki
}

Received: 3 March 2010 /Revised: 2 November 2010 / Accepted: 26 November 2010 /Published online: 23 December 2010

(C) The Author(s) 2010. This article is published with open access at Springerlink.com

\begin{abstract}
Beavers strongly modify their environment by not only building dams and creating ponds, which slow the water flow, but also by selective cutting and removing of trees, which change the spatial structure of the forest. We aimed to test the hypothesis that beaver activity promotes new foraging sites for insectivorous bats. The beaver's influence can be especially significant on aerial hawkers that prefer moderate structural clutter, like the Pipistrellus species (by creating new canopy gaps), and on water-surface foragers, like Myotis daubentonii (by creating ponds with smooth water surface). The study was conducted on small streams in forest areas of northern Poland, which were colonized by the European beaver (Castor fiber). Bat activity was recorded with a Pettersson D-980 ultrasound detector on line transects. The number of bat passes was significantly higher in the stream sections modified by beavers (flooded and subjected to intensive tree cutting) than in the unmodified sections (for Pipistrellus nathusii, Pipistrellus pipistrellus, Pipistrellus pygmaeus, Nyctalus noctula, and all species lumped together). Contrary to our expectations, the activity of the Myotis species was significantly lower on the
\end{abstract}

\footnotetext{
Communicated by C. Gortázar

M. Ciechanowski $(\bowtie) \cdot$ W. Kubic $\cdot$ A. Rynkiewicz $\cdot$ A. Zwolicki Department of Vertebrate Ecology and Zoology, University of Gdańsk,

al. Legionów 9,

PL 80-441 Gdańsk, Poland

e-mail: matciech@kki.net.pl

W. Kubic

e-mail: weronikarogalska@wp.pl

A. Rynkiewicz

e-mail: olarynkiewicz@gmail.com

A. Zwolicki

e-mail: prosoche@poczta.onet.pl
}

transect with the largest beaver ponds, possibly due to the blanket of duckweed (Lemnaceae), which is known to produce clutter echoes, thereby reducing prey detection by echolocating $M$. daubentonii.

Keywords Castoridae $\cdot$ Chiroptera $\cdot$ Ecosystem engineer . Habitat use $\cdot$ Keystone species

\section{Introduction}

Species that strongly modify the structure of phytocoenoses, topography, geomorphology, and water conditions affect almost all elements of local ecosystems, and thus may be regarded as keystone species (Paine 1969) and ecosystem engineers (Jones et al. 1994). Canadian beaver Castor canadensis and European beaver Castor fiber may serve as an example. Their ability to modify river valley ecosystems has no equivalent in the animal kingdom; thus serious conflicts associated with both economy and conservation have emerged in several parts of beavers' geographic range (Baker and Hill 2003). On the other hand, their activity favors regeneration of degraded habitats and increase of biological diversity at a local scale (Rosell et al. 2005). Foraging of woody plants by beavers creates canopy gaps, decreases canopy cover and (if shrubs are also eaten) may decrease density of undergrowth. They not only change the spatial structure of plant communities but also change species composition at the herb layer (Zwolicki 2005; Hood and Bayley 2009). Beavers also build dams, which create extensive water bodies ("beaver ponds") that protect entrances to their lodges or burrows (Baker and Hill 2003). Flooding caused by beavers changes water conditions by altering hydrochemistry, increasing water storage and sedimentation rates, and facilitating the development of 
ecotones at the riparian edges (DeBano and Heede 1987; Gurnell 1998; Butler and Malanson 2005; Rosell et al. 2005). They could also increase the number of standing dead, often hollow, trees.

Modifications of habitat conditions by beavers affect also species diversity of animal assemblages and population sizes of particular species. Damming and consequent flooding of stream valleys by beavers increase species diversity or population density of mustelids (Sidorovich et al. 1996), wetland birds, especially waterfowl (Nummi 1992; Grover and Baldassarre 1995; Nummi and Poysa 1997); amphibians (Russell et al. 1999; Dalbeck et al. 2007; Stevens et al. 2007; Popescu and Gibbs 2009), cyprinid fish (Collen and Gibson 2000), lenitic insects (e.g., dragonflies and chironomids), bivalves, leeches, oligochaetes and some crustaceans (McDowell and Naiman 1986; Nummi 1989; Nummi 1992; Collen and Gibson 2000). However, the response of particular taxa to beaver activities can be diverse and related to species-specific preferences. For example, beaver damming decreases frequency and species diversity of salamanders, but increases these parameters in frogs (Metts et al. 2001; Stevens et al. 2007). It may also contribute to the decline of lotic species-mayflies, net-spinning caddisflies, stoneflies, and salmonid fish (McDowell and Naiman 1986; Nummi 1989; Collen and Gibson 2000; Rosell et al. 2005). In general, most studies focus on the impact of flooding caused by beavers on aquatic or semi-aquatic animal species. Only few studies examine the effect of beaver activities on terrestrial animals, although tree cutting and brush grazing may benefit some phytophagous forest beetles (Martinsen et al. 1998) and riparian vegetation developed in beaver ponds attract even large ungulates (Rosell et al. 2005; Baker et al. 2005; Hood and Bayley 2008). In general, the net effect of beaver colonization on biodiversity is considered positive, so reintroduction of beavers is often proposed as a relatively cheap method of wetland restoration in heavily disturbed ecosystems (Baker and Hill 2003). European beaver - formerly absent or endangered in many countries of its native range - is recently expanding by human reintroduction and natural dispersal, again becoming a common element of local faunas (Halley and Rosell 2003) and, presumably, increasing its impact on the ecology of riparian habitats.

Bats of the temperate zone are among animals that might be modified by beaver activity. They are almost exclusively insectivorous (Vaughan 1997) and concentrate their foraging activity in habitats of the highest prey abundance (e.g., in river valleys), where they benefit from emerging aquatic insects (Fukui et al. 2006). Riparian zones and water bodies usually hold the highest diversity of bats and the highest density of foraging individuals (Rachwald 1992; Rydell et al. 1994; Walsh and Harris 1996; Vaughan et al. 1997a; Grindal et al. 1999; Russ and Montgomery 2002; Ellison et al. 2005; Menzel et al. 2005a). In the diet of several species, like Daubenton's bat (Myotis daubentonii), pipistrelles (Pipistrellus spp.) or noctules (Nyctalus spp.), insects whose larvae develop in water may dominate (Vaughan 1997; Rydell and Petersons 1998). However, bats' adaptations to particular hunting tactics bring serious limitations regarding the use of various habitats, even those supporting extremely abundant prey. Aerial hawkers may capture prey only in some distance from obstacles, e.g., tree crowns (Baagøe 1987; Jones 1995; Kalko 1995). Therefore, their foraging might not be effective in dense tree stands and their activity is negatively correlated with stand density (Erickson and West 2003). Some species (e.g., M. daubentonii), adapted to hawking insects just above the water or even gaffing them directly from its surface (Jones and Rayner 1988; Todd and Waters 2007), benefit from an acoustic mirror effect (Siemers et al. 2005). However, they cannot detect prey if water surface is turbulent, as frequently occurs in shallow and narrow streams (Mackey and Barclay 1989; Rydell et al. 1999), or if it is covered by floating vegetation (i.e., pleustophytes) (Boonman et al. 1998; Ciechanowski et al. 2007). Bats reveal clear microhabitat preferences, dependent on their foraging tactics. In forests, aerial hawkers hunt mostly in canopy gaps, on glades, in ecotones (Kusch et al. 2004), or in corridors formed by streams and trails, which are apparently used as flyways to avoid high clutter (Lloyd et al. 2006). Some species prefer calm sections of rivers and avoid those with fast current (Warren et al. 2000).

Damming of water courses by beavers reduces stream velocity and increases flooding outside the original channel (Rosell et al. 2005) while selective removal of trees (Zwolicki 2005) forms canopy gaps and reduces density of undergrowth (i.e., vertical obstacles). These modifications may increase attractiveness of a beaver-inhabited valley as a foraging site for several bat species. In general, distribution of hunting bats along rivers and streams relates to the spatial structure of riparian vegetation (Warren et al. 2000; Downs and Racey 2006), physical characteristics of the current (Rydell et al. 1999; Warren et al. 2000), and water quality (Vaughan et al. 1996; Biscardi et al. 2007; KalcounisRueppell et al. 2007), which are all features known to be modified by beavers (Rosell et al. 2005). Documenting relationships between bats and beavers would support the hypothesis about the keystone function of beavers in such ecosystems that is justified based on data about the impact of beavers on the other groups of fauna and flora (Rosell et al. 2005). However, no such effect on bats has ever been documented, although some publications mention the use of beaver-modified habitats by chiropterans. Among Appalachian wetlands, the highest activity of Myotis lucifugus was recorded at a site containing a permanent, 2-ha beaver pond (Francl et al. 2004). The so-called "beaver meadows" (former ponds filled with sediments and overgrown with 
herbaceous vegetation) support moderate bat activity among the acoustically surveyed habitats of Massachusetts (Brooks and Fords 2005). Radio-tracking studies revealed that evening bats (Nycticeius humeralis) roost under exfoliating bark on dead snags in beaver ponds (Menzel et al. 2001).

The recognition of links between the spatial structure of habitat and distribution of foraging sites acts as a base for conservation and management of bat populations in anthropogenically altered landscapes (Brinkmann and Limpens 1999). Assessment of beavers' impact on various elements of local biota supports the hypothesis about their function as keystone species and ecosystem engineer, thus providing arguments for proper management decisions (including that of reintroduction). The objective of this study was to compare the foraging and commuting activity of vespertilionid bats among sections of small, forested river valleys modified and unmodified by European beavers. We hypothesized that (1) both aerial hawking and water-surface foraging (trawling) species would be more active at sections flooded by beaver dams than at the sections with unmodified streams; (2) aerial hawkers would additionally reveal higher levels of activity at sections with extensive cutting of trees by foraging beavers than in uniform, unmodified stands.

\section{Materials and methods}

Study area

The study was conducted in the forested valleys of two small watercourses in Bory Tucholskie (vicinity of Osiek), Pomeranian Lakeland, northern Poland. The last beavers in the country of study became extinct by about 1844 , and remained so, until a series of successful reintroductions and translocations between 1943-1949 and 19751986 (Halley and Rosell 2003). Both streams are tributaries of the Wda river, itself belonging to the Vistula river catchment area. Beavers were reintroduced in that area in 1971 and since then have colonized spontaneously almost the whole drainage area of Wda. Both valleys are surrounded by heavily managed, uniform monocultures of Scotch pine (Pinus sylvestris) with poorly developed vertical structure.

Site 1 was located in a valley with a small brook near Stara Rzeka village $\left(53^{\circ} 39^{\prime} 21.72^{\prime \prime} \mathrm{N}, 18^{\circ} 17^{\prime} 6.82^{\prime \prime} \mathrm{E}\right)$. The brook itself was about $1-\mathrm{m}$ wide, very shallow (average depth, below $10 \mathrm{~cm}$ ) and rapid, but with very small discharge. It flows through the wide meadow and dense, mature broadleaf forests. Pedunculate oak Quercus robur, hornbeam Carpinus betulus, aspen Populus tremula, and Norway spruce Picea abies dominate valley slopes, but black alder (Alnus glutinosa) and birch (Betula pendula) dominate closer to the stream. Activity of beavers, including construction of four dams more than 100-m long, led to an extensive flooding, which covered a few hectares of riparian forest and meadow with patches of reed beds. From May to late autumn, these beaver ponds were covered almost completely by duckweed (mostly Lemna minor). Beavers also cut many trees on the slopes and the bottom of the valley, which significantly thinned out the stand at a distance up to a few dozens of meters from the water edge.

Site 2 was located in a valley with a stream near

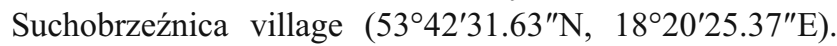
The stream was wider $(2-3 \mathrm{~m})$ and had much higher discharge, velocity, and depth up to $50 \mathrm{~cm}$. The stream cuts through dense stands of black alder and Scotch pine forest with mixture of aspen, birch, and Norway spruce. Beavers constructed a series of eight small dams (usually not exceeding $20 \mathrm{~m}$ in length) that formed a chain of small ponds (less than 0.1 ha each). They remained free of duckweed during the whole study period, but water levels fell notably during mid-summer because of a decrease in precipitation, so the few largest ponds became overgrown by emergent vegetation, mostly cutleaf water parsnip (Berula erecta). The impact of beavers on trees appears to be lower than in Stara Rzeka (Site 1). The modifications were restricted to flooding and the death of a narrow forest strip in the lower section of the valley and the cutting of some trees, which resulted in the creation of localized canopy gaps.

\section{Recording of bat activity}

In each valley, a linear transect was marked parallel to the stream channel to record echolocation calls of commuting and foraging bats. At site 1, the transect was 1,210 m long (walked in $35 \mathrm{~min}$ ) and divided into 11 sections: three unmodified by beavers $(40 \%$ of total length-brook flowing freely through a meadow and dense forest) and eight modified $(60 \%$ transect-flooded meadow, flooded forest with dead snags, dams, tree cuttings, and resulting canopy gaps). At site 2, the transect was 1,660 m long (walked in $30 \mathrm{~min}$ ) and divided into 16 sections, covering subsequent beaver ponds (i.e., the first $50 \mathrm{~m}$ above each dam) and unmodified fragments of the stream with a notably faster current.

The activity of bats in both valleys was studied during spring (April-May), summer (June-July), and early autumn (September). In total, site 1 was visited 22 times and site 2 was visited 21 times from 2005 to 2007 . Only one site was visited per evening. Bat echolocation calls were recorded using a Pettersson D-980 (Pettersson Elektronik AB; Uppsala, Sweden) bat detector attached to a Sony WMD6C stereo tape recorder. The detector worked in real-time (retained amplitude frequency division) mode, and calls of 
frequency divided by 10 were recorded constantly on the left channel if the original sound fell into range, $10-200 \mathrm{kHz}$. At any time, when signals of passing bats were heard in the frequency divider, a person that conducted recording triggered the time-expansion mode (range, $10-150 \mathrm{kHz}$ ) to preserve all characteristics of the recorded ultrasound. In this mode, the detector sampled at $350 \mathrm{kHz}$ with 8 bits of resolution, storing was selected at $3.0 \mathrm{~s}$ of sound in digital memory and played it back, time-expanded by a factor of 10. A full spectrum sample was subsequently recorded on the right channel, parallel to real-time frequency division recording. Every sequence of at least two calls recorded on one of the two channels (either frequency-divided or time-expanded) was considered a bat pass. Each time, the transect was walked twice in the evening. The first walk began half an hour after sunset (Rachwald 1992; Warren et al. 2000) while the second walk began immediately after the end of the first. Such an approach allowed us to record activity of several species that differ in timing of evening emergence from daily roosts (cf. Jones and Rydell 1994).

\section{Bioacoustic analysis of bat calls}

Recorded echolocation calls, attributed to particular sections of the transects were downloaded as audio files into a computer using BatSound 3.3 (Pettersson Elektronik AB; Uppsala, Sweden) at $22.5 \mathrm{kHz}$ with 16 bit resolution. The calls were analyzed using a 1024-point fast Fourier transform, hanning window. We based species recognition on tonal quality (shape) of the calls (based on spectrogram), peak frequency or frequency of maximum energy (measured on power spectrum), pulse duration, and interval length (measured on oscillogram). All extracted parameters and additional diagnostic features were compared with those available in the literature (Ahlén 1990; Barataud 1996; Vaughan et al. 1997b). Echolocation calls of various Myotis species are similar in structure, thus hard to identify reliably, so we classified them into one group (Myotis sp.). However, the identification of recorded individuals as $M$. daubentonii at site 2 was in several cases, confirmed by observations of a specific hunting style which included circling repeatedly just a few centimeters above the water surface (Ahlén 1990). Congenerics were thereby ruled out based on visual observation. Both Myotis mystacinus and Myotis brandtii are extremely rare species in the region and no breeding has been confirmed there for the latter (Sachanowicz et al. 2006). We have never recorded the exceptional broadband signals of Myotis nattereri, which may be considered diagnostic (mean bandwidth, $119 \mathrm{kHz}$; Siemers and Schnitzler 2004). Therefore, it is highly probable that either the only representative of Myotis genus in the study area was $M$. daubentonii or the occurrence of its congenerics was negligible.
Statistical analysis

Because the assumptions of normality were violated in several subsets of data, we tested all differences in bat activity, using non-parametric statistics: Mann-Whitney $U$ test between sites, Wilcoxon signed-rank test between sections of transects generally classified as modified or unmodified by beavers, and Friedman's ANOVA among sections assigned to different original habitats (meadow, intact forest) as well as different types and levels of beaver impact (tree cuttings-canopy gaps, flooding-beaver ponds, lack of visible modification). In every case, the number of bat passes per $100 \mathrm{~m}$ was defined as a response (dependent) variable. Predictor (independent) variable in Friedman's ANOVA was defined as a habitat type (five categories: (1) forest, (2) flooded forest with canopy gaps created by beavers, (3) forest with beaver-created canopy gaps but no flooding, (4) meadow, and (5) flooded meadow). Only nights, when a particular taxon appeared on a transect, were taken for such comparisons. Additionally, species composition (proportion of passes) between sites was compared using Pearson's chi-squared test and species diversity (H' Shannon-Wiener index) between sites was compared using the modified $t$ test (Zar 1996). We performed all the analyses using Statistica 6.0 (StatSoft, Inc.) except the comparison of H'index that was performed using Microsoft Excel 2003. Statistical significance was accepted at $P<0.05$.

\section{Results}

In total, seven species of bats were recorded on both transects: Daubenton's bat $M$. daubentonii (including those determined as Myotis sp.), serotine Eptesicus serotinus, common pipistrelle Pipistrellus pipistrellus, soprano pipistrelle Pipistrellus pygmaeus, Nathusius' pipistrelle Pipistrellus nathusii, noctule Nyctalus noctula, and brown long-eared bat Plecotus auritus. Species composition differed significantly between sites $\left(\chi^{2}=103.65, \mathrm{df}=6\right.$, $p<0.0001)$. At site 1 , the most numerous species was $P$. nathusii, followed by $P$. pipistrellus and $N$. noctula while activity of Myotis bats was almost negligible. On the contrary, at site 2 , the most numerous were representatives of the Myotis genus, followed by $P$. pipistrellus and P. nathusii (Table 1). Both sites also differed in species diversity, being slightly lower at site $2(t=2.18, \mathrm{df}=463$, $p=0.03)$. The density of bat passes was significantly higher at site 1, regarding all taxa combined (Mann-Whitney $U$ test: $U=75.00, Z=3.52, p=0.0004), P$. pipistrellus $(U=73.50, Z=3.56, p=0.0004), P$. pygmaeus $(U=93.00$, $Z=3.05, p=0.002), P$. nathusii $(U=53.50, Z=4.08$, $p=0.00004)$, and $N$. noctula $(U=68.00, Z=3.70, p=0.0002)$, 
Table 1 The total number of passes of particular species in each site, density of bat passes per $100 \mathrm{~m}$ (median+range), and species diversity indices

\begin{tabular}{|c|c|c|c|c|c|c|}
\hline \multirow[t]{3}{*}{ Species } & \multicolumn{3}{|l|}{ Site 1} & \multicolumn{3}{|l|}{ Site 2} \\
\hline & \multirow[t]{2}{*}{ Number } & \multicolumn{2}{|l|}{ Density } & \multirow[t]{2}{*}{ Number } & \multicolumn{2}{|l|}{ Density } \\
\hline & & Median & Range & & Median & Range \\
\hline Myotis sp. & 13 & $<0.01$ & $0.00-0.33$ & 87 & 0.18 & $0.00-1.20$ \\
\hline Eptesicus serotinus & 25 & 0.08 & $0.00-0.50$ & 30 & $<0.01$ & $0.00-0.84$ \\
\hline Pipistrellus pipistrellus & 334 & 1.16 & $0.00-4.71$ & 57 & 0.09 & $0.00-1.32$ \\
\hline Pipistrellus pygmaeus & 393 & 1.16 & $0.00-5.37$ & 6 & 0.06 & $0.00-0.60$ \\
\hline Pipistrellus nathusii & 87 & 0.25 & $0.00-2.15$ & 44 & $<0.01$ & $0.00-0.30$ \\
\hline Pipistrellus sp. & 55 & 0.17 & $0.00-0.66$ & 9 & $<0.01$ & $0.00-0.24$ \\
\hline Nyctalus noctula & 193 & 0.33 & $0.00-2.89$ & 14 & $<0.01$ & $0.00-0.66$ \\
\hline Plecotus auritus & 2 & $<0.01$ & $0.00-0.08$ & 7 & $<0.01$ & $0.00-0.12$ \\
\hline Indeterminate bats & 27 & 0.08 & $0.00-0.58$ & 18 & 0.03 & $0.00-0.24$ \\
\hline Total & 1,129 & 3.06 & $0.00-13.80$ & 272 & 0.51 & $0.12-2.94$ \\
\hline Diversity index (H') & 0.80 & & & 0.75 & & \\
\hline
\end{tabular}

but the Myotis species were more active at site $2(U=$ 83.00, $Z=-3.31, p=0.0009)$. There were no differences in density at either site for E. serotinus $(U=171.00, Z=1.02$, $p=0.30)$ or $P$. auritus $(U=178.50, Z=-0.82, p=0.41)$.

The number of bat passes was significantly higher in sections of valleys modified by beavers than in unmodified sections (Wilcoxon matched pairs test, site 1: $n=19, T=$ $0.00, Z=3.82, p=0.0001$, Fig. 1 ; site $2: n=20, T=52.00, Z=$ $1.98, p=0.048$, Fig. 2). When regarding particular species separately, four species occurred frequently enough at site 1 to perform such comparison and all revealed higher activity in sections modified by beavers (P. pipistrellus: $n=18$,

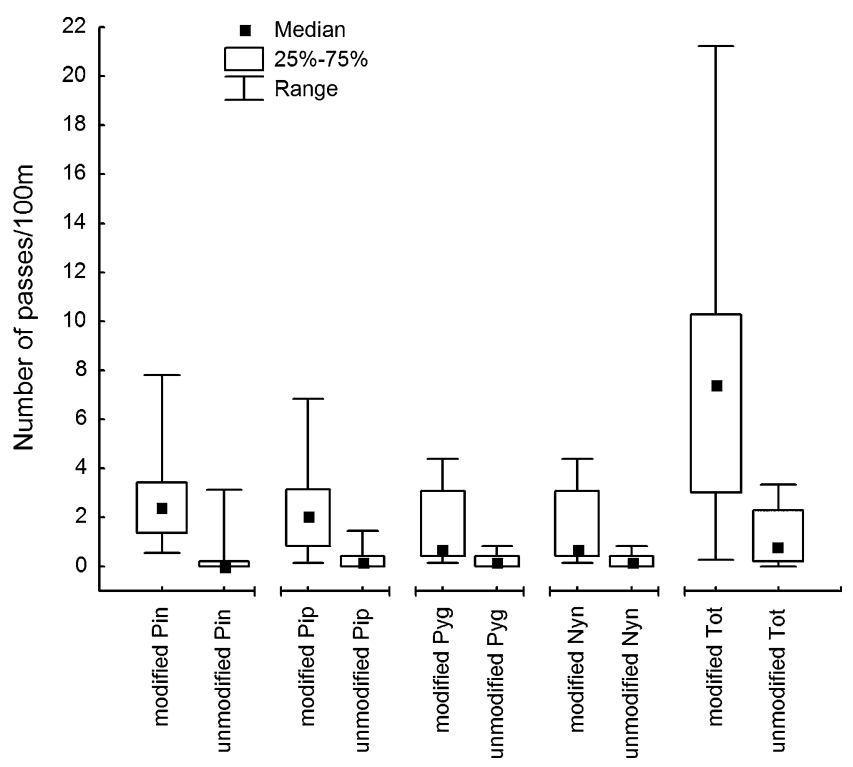

Fig. 1 Differences in bat activity between sections of the valley modified and unmodified by beaver's flooding and cutting activities at site 1. Pin, P. nathusii; Pip, P. pipistrellus; Pyg, P. pygmaeus; Nyn, Nyctalus noctula; Tot, the total number of all bat passes, including indeterminate calls
$T=1.00, Z=3.68, p=0.0002 ;$ P. pygmaeus: $n=13, T=8.00$, $Z=2.62, p=0.008 ; P$. nathusii: $n=18, T=0.00, Z=3.72$, $p=0.0002 ; N$. noctula: $n=16, T=0.00, Z=3.52, p=0.0004$, Fig. 1). Only two species were frequent enough to compare modified and unmodified sections at site 2 , and none of them revealed a significant difference in activity (Myotis species: $n=16, T=48.00, Z=1.03, p=0.30 ;$ P. pipistrellus: $n=13, T=40.00, Z=0.38, P=0.70$, Fig. 2).

Bat activity, in particular habitats at site 1 , differed significantly (Friedman's ANOVA: $n=20, \chi^{2}=39.79$, df $=4$, $p=0.00001$ ) with the highest number of passes in flooded forest with canopy gaps created by beavers. Significantly

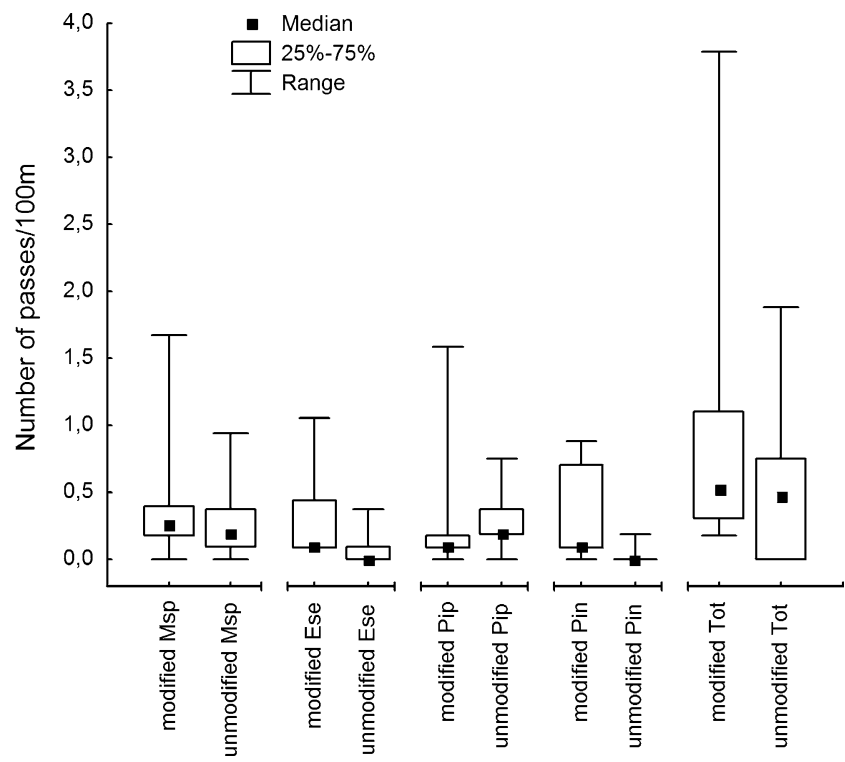

Fig. 2 Differences in bat activity between sections of the valley modified and unmodified by beaver's flooding and cutting activities at site 2. Msp, Myotis spp.; Ese, Eptesicus serotinus; Pin, P. nathusii; Pip, P. pipistrellus; Tot, the total number of all bat passes, including indeterminate calls 
fewer passes were recorded in a forest with canopy gaps only and in intact unmodified forest. Meadows flooded by beavers were used more intensively than unflooded meadows (Fig. 3e). The same result was obtained for P. nathusii $\left(n=18, \chi^{2}=39.72, \mathrm{df}=4, p=0.00001\right)$, including similar paired comparisons between habitats (Fig. 3c).
Activity of $P$. pipistrellus differed significantly between habitats $\left(n=18, \chi^{2}=24.42, \mathrm{df}=4, p=0.00007\right)$, with more passes being recorded in the flooded forest with cuttings than in the intact forest and more passes over flooded meadows than over the unflooded meadow (Fig. 3a). A variation in activity of $P$. pygmaeus among habitats was
Fig. 3 Differences in bat activity between particular habitats distinguished along the transect at site $1 . F$, forest; $F F G$, flooded forest with canopy gaps created by beavers; $F G$, forest with beaver-created canopy gaps but no flooding; $M$, meadow; $M F$, flooded meadow. Arrows indicate significant differences $(p<0.05)$ revealed in post hoc tests
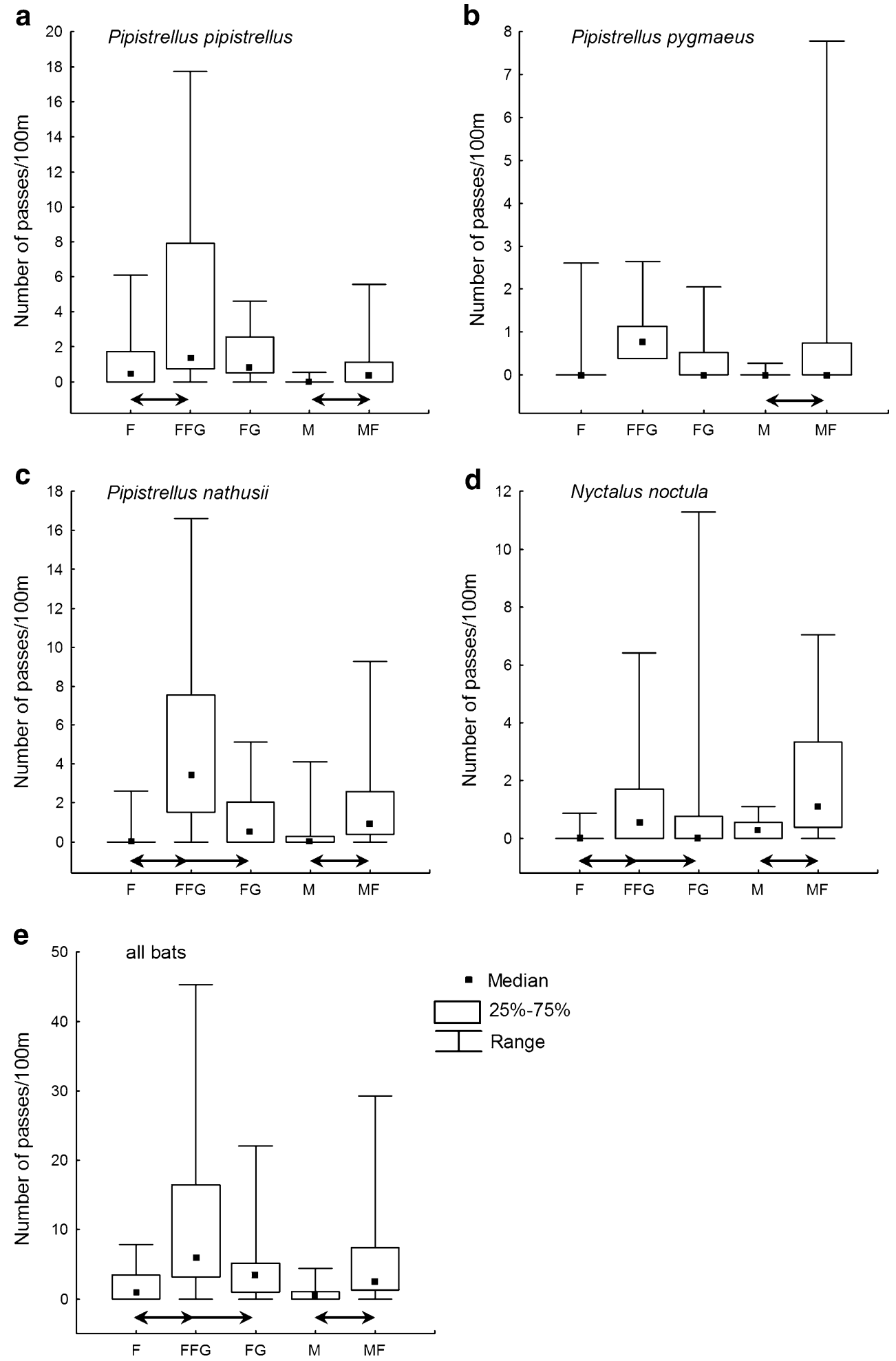
also significant $\left(n=13, \chi^{2}=18.77, \mathrm{df}=4, p=0.0009\right)$ but only the number of passes over flooded and dry meadows differ significantly in paired comparison (Fig. 3b). The notable exception was $N$. noctula $\left(n=16, \chi^{2}=24.29\right.$, $\mathrm{df}=4$, $p=0.00007$ ) that revealed the highest median activity not in flooded forest with gaps, but over the flooded meadow. Significantly, more passes of $N$. noctula were recorded in the latter habitat than over the meadow that was not flooded. In addition, increased activity appeared in flooded forests where beavers cut trees than in forests with cut trees but no flooding, or in forests not modified by beavers (Fig. 3d). Although we revealed differences between modified and unmodified sections of the transect at site 2 , no similar distinction among habitat types was possible there. All the original habitat appeared to be dense, intact forest, and any visible effect of beaver activity was restricted to flooding of a narrow strip along the stream and dispersed tree cuttings.

\section{Discussion}

We found that the nightly activity of vespertilionid bats at the two sites of northern Poland was higher in sections of small river valleys visibly transformed by recently reintroduced European beavers (i.e., flooded and with tree cuttings) than in sections of the same valleys not subjected to such transformations. Our study is the first to document significant effects of beavers' foraging and building activities on spatial distribution of foraging or commuting bats. However, it confirmed our expectations only partially, with respect to aerial hawking species, but not watersurface foragers (i.e., groups that might benefit from the different aspects of beaver activity).

Occurrence of more bats in areas modified by beavers at both sites reduced the possibility that observed differences were due to chance alone. Accurate quantification of a sitespecific magnitude of bat activity at rivers and ponds can be achieved with a sampling intensity of at least 14 nights (Broders 2003), and our sample size exceeded that value by more than one third. It is also highly unlikely that increased activity of bats in some sections of the transect was related to location of daily roosts from which bats emerged during recordings, even if the use of riverine habitats by hunting chiropterans is known to correlate negatively with the distance from nursery colonies (Dietz et al. 2006). Although trees killed by flooding by beavers can be used as roosts by some forest bats (Menzel et al. 2001), timing of survey largely excluded such possibility. Significant differences in the number of passes between modified and unmodified sections were produced mostly by predominant, aerial hawking taxa (Pipistrellus, Nyctalus and, less importantly, the Eptesicus genus) that are known to emerge
8 to 32 min after sunset, on an average (Jones and Rydell 1994). Thus, when the outward leg of the transect was walked, most bats had already emerged and their presence or absence in particular parts of the studied valleys was related to the attractiveness of the habitat as a foraging site or a flyway.

There are at least two main factors that may explain the higher activity levels of bats in sections subject to habitat modifications caused by beavers. The first, apparently more obvious, is flooding (i.e., increase in water table and creation of beaver ponds, covering former terrestrial habitats). All four species that revealed significant differences between sections of the transect at site 1 (P. pipistrellus, P. pygmaeus, $P$. nathusii, $N$. noctula) are known to prefer water bodies or riparian zones (Rachwald 1992; Rydell et al. 1994; Vaughan et al. 1997a; Mickevičiené and Mickevičius 2001; Russ and Montgomery 2002; Downs and Racey 2006; Kaňuch et al. 2007). As beavers extend riparian habitats, they improve the habitat quality for bats and provide them with large areas where prey is much more abundant than over the shallow and narrow streams. Moreover, biomass of emerging chironomids, an important prey of Pipistrellus and Nyctalus (Vaughan 1997), increased in the valley section after construction of a beaver dam, at least during the first few years (Nummi 1989). The second factor is related to a significant reduction of forest-associated clutter, being a serious limitation for aerial hawking species. Although woodlands, especially deciduous ones, are among the most preferred habitats by bats, along with riparian zones (Walsh and Harris 1996; Russ and Montgomery 2002), closer examination reveals that most aerial hawking bats avoid internal parts of dense, intact stands (Rachwald 1992; Lloyd et al. 2006). Their activity is negatively correlated with the area of closed canopy (Kusch et al. 2004) and density of trees (Erickson and West 2003). In managed forests that are subject to commercial logging, aerial hawkers use either stream corridors (Lloyd et al. 2006) or artificial areas of low clutter, which include thinned stands, clear-cuts (Patriquin and Barclay 2003), and trails (Lloyd et al. 2006). In unmanaged and unharvested forests, the same group of bats have to use natural canopy gaps that are usually created by the aging of older trees, windthrows, outbreaks of phytophagous insects, and pathogenic fungi (Weiskittel and Hix 2003; Worrall et al. 2005). Cutting of trees by beavers may have a similar function in forests adjacent to water bodies and wetlands inhabited by these rodents.

We cannot explicitly indicate which of the two, mentioned above, effects of beavers on the ecosystem of the small river valley has the greater impact on insectivorous bats. Moreover, they appear to act additively. The total activity of bats, as well as specifically that of $P$. nathusii and $N$. noctula, was significantly higher in forests with beaver-created canopy gaps than in dense, unmodified 
forest, which suggests that beaver foraging (and tree cutting) may separately improve habitat quality for hunting bats, thus confirming our first hypothesis. However, the activity of bats was also significantly higher in the flooded forest with gaps than in the non-flooded forest with gaps only. Flooding may also act independently as a factor promoting the use of habitat by bats, as evidenced by higher activity of all four species over the flooded part of the meadow than over the section outside of the beaver pond. This difference is especially important in N. noctula, an open-space forager with low maneuverability that hunts at high altitude, far from any vertical obstacles (Baagøe 1987; Jones 1995). The latter species may rely more on wide meadows, subjected solely to flooding than on beavercreated forest gaps, although a difference between the two most important habitats for noctules in our study was not significant. On the contrary, Pipistrellus spp. commute and hunt in quite a maneuverable style and are able to circle around trees at much lower altitude (Baagøe 1987; Kalko 1995), at least, if clutter is moderately reduced. They may prefer a combination of flooding and tree cutting found in beaver ponds with numerous snags, which are remains of the riparian forest, partially immersed in water after damming. The activity of pipistrelles appears to be the highest in close proximity to tree lines and gradually decreases at greater distances from them (Downs and Racey 2006). Thus, the forest habitats altered by beavers may be more frequently used than beaver-transformed open habitats.

We were unable to confirm our hypothesis that damming of the stream increase habitat use by water-surface foragers (e.g., M. daubentonii) due to the formation of large areas of smooth water, which serve as an acoustic mirror for prey detection. The activity of the Myotis species was almost negligible at site 1, with no difference between flooded and non-flooded sections. However, all beaver ponds at that site were completely covered by a dense, floating layer of pleustophytic vegetation, mostly formed by duckweed (Lemnaceae). A much lower discharge and stream velocity excluded the effective removal of these plants, which were absent on the ponds' surface only during April, when no bats forage there probably due to low air temperatures. Duckweed is known to produce significant acoustic clutter that suppresses foraging of $M$. daubentonii by producing complicated background echoes that interfere with a bat's prey detection (Boonman et al. 1998), thus it may also negate any benefits to trawling bat species from the creation of ponds by beavers in some areas. The same reasoning also applies to other kinds of floating vegetation (Ciechanowski et al. 2007). The effect of pleustophytes on bat activity over beaver impoundments may not be obligatory, and streams with a higher velocity of current and stronger flow probably remove floating vegetation, thus keep the surface of beaver ponds free of duckweed. A notable example of such a situation appeared to be in site 2 , where the activity of Myotis species was significantly higher than at site 1, and this taxon dominated in local bat assemblage. Moreover, we directly observed the individuals of $M$. daubentonii hunting over the surface of small, duckweed-free beaver ponds just above the dams. Although we were unable to obtain a significant difference between dammed and untransformed sections of the stream for these species, this may be a result of generally low bat activity at site 2 , thereby reducing samples often to just few passes each night, which makes differences between data points sensitive to stochastic variation. Future comparative studies repeated at more sites might document preference of dammed valley sections by any water-surface bat species. This phenomenon may especially apply to the older ponds. Duckweed achieves the greatest surface coverage in youngest impoundments (less than 10 years after damming), but declines afterwards, replaced by larger macrophytes (lily pads) and finally, after about 40 years, some ponds establish vegetation that lack significant floating cover (Ray et al. 2001). The latter may become available foraging habitat for trawling bat species.

Confirmation of our first hypothesis provided a strong argument that reintroduction of the beaver to the small river valleys may improve habitat quality for aerial hawking insectivorous bats, thus reintroduction might be recommended with respect to bat conservation. Bats are known to benefit from restoration of formerly drained wetlands, as indicated by an increase in activity on areas subjected to such treatment (Menzel et al. 2005b). Usually, active riparian restoration is applied to obtain such results, including vegetation plantings, creation of small clearings to mimic natural disturbances and development of canopy gaps, placement of coarse woody debris on floodplain and in stream corridors, reconfiguring channelized riches to increase their sinuosity and floodplain connectivity (Kauffman et al. 1997; Roni et al. 2002), and closing drainage ditches with earthen plugs (Menzel et al. 2005b). These methods are often costly and time-consuming; thus, reintroduction of a keystone species, such as the beaver, appears to be a reasonable option, which is cost-effective and leads to the restoration of a whole ecosystem of a small river valley. They not only create new foraging sites for bats, but also increase the influx of emerging aquatic insects to surrounding forests, as usually observed in situations where any water body contact with the woodland (Nakano and Murakami 2001), thus they may benefit even bat species that prefer to hunt under a canopy rather than over a riparian strip. Finally, maternal colonies of bats are known to aggregate in close vicinity of proper foraging sites (Dietz et al. 2006), so beaver activities may increase suitability of surrounding roosting habitats as well. The expected effect may appear in a short time after colonization by beavers because bats often start to 
exploit new sources of food in an astonishingly short time (Fenton and Morris 1976).

It has to be noted, however, that beavers might benefit bats regarding foraging habitats only in valleys of small streams because larger rivers intersecting forest areas provide corridors and act as linear canopy gaps with smooth water surfaces at the bottom, wide enough to support hunting by both aerial hawkers and trawling bats. In such situations, further reduction of clutter, associated with tree cutting on valley slopes, would be of negligible importance. Locally, some negative effects of beaver reintroduction on local bat assemblages might also be expected, as beavers select trees mostly at closest distance from the water (Haarberg and Rosell 2006), whereas in open agricultural landscapes, bats forage mostly along river sections lined with trees from both sides (Warren et al. 2000; Downs and Racey 2006). Extensive removal of such tree lines would lead, in fact, to degradation of bat foraging habitats. Although this is not the case of forest landscapes, where bats react positively on moderate tree removal due to reduction of clutter, there are notable exceptions. Some clutter-adapted, gleaning species require high coverage of stand canopy (Ford et al. 2005). However, even if beaver reintroduction is regarded as beneficial for bat populations at a particular site, it must be weighed against other natural values of the particular area.

In formerly drained, degraded valleys, colonization by beavers is considered to enhance strongly their biodiversity; however, when the valley holds the last remnants of natural forest among large blocks of heavily managed plantation, foraging beavers may cause their final degradation (Zwolicki 2005). Moreover, some of the most sensitive, strictly rheoand oxybiontic species of freshwater invertebrates might even be threatened by beaver dams and the resulting silt deposition (Rosell et al. 2005). Despite these arguments, the presence of beavers should be included in any assessments of bat habitat potential in small river valleys, bearing in mind that, until recently, links between beavers' ecosystem engineering and distribution of bats have been neglected both in North America and in Europe.

Acknowledgements The study was supported by an internal grant of the University of Gdańsk BW/1440-5-0230-5.

Open Access This article is distributed under the terms of the Creative Commons Attribution Noncommercial License which permits any noncommercial use, distribution, and reproduction in any medium, provided the original author(s) and source are credited.

\section{References}

Ahlén I (1990) Identification of bats in flight. Swedish Society for Conservation of Nature and Swedish Youth Association for
Environmental Studies and Conservation. Kataryna Tryck Ab Press, Stockholm

Baagøe HJ (1987) The Scandinavian bat fauna: adaptive wing morphology, and free flight in the field. In: Fenton MB, Racey PA, Rayner JMV (eds) Recent advances in the study of bats. Cambridge University Press, Cambridge, pp 57-74

Barataud M (1996) The world of bats. Acoustic identification of French bats. Sittelle Publishers, Mens

Baker BW, Hill EP (2003) Beaver Castor canadensis. In: Feldhamer GA, Thompson BC, Chapman JA (eds) Wild mammals of North America: biology, management, and conservation. The John Hopkins University Press, Baltimore, pp 288-310

Baker BW, Ducharme HC, Mitchell DCS, Stanley TR, Peinetti HR (2005) Interaction of beaver and elk herbivory reduces standing crop of willow. Ecol Appl 15:110-118. doi:10.1890/03-5237

Biscardi S, Russo D, Casciani V, Cesarini D, Mei M, Boitani L (2007) Foraging requirements of the endangered long-fingered bat: the influence of micro-habitat structure, water quality and prey type. J Zool 273:372-381. doi:10.1111/j.1469-7998. 2007.00337.x

Boonman AM, Boonman M, Bretschneider F, van de Grind WA (1998) Prey detection in trawling insectivorous bats: duckweed affects hunting behaviour in Daubenton's bat, Myotis daubentonii. Behav Ecol Sociobiol 44:99-107. doi:10.1007/s002650050521

Brinkmann R, Limpens HJGA (1999) The role of bats in landscape planning. Trav Sci Mus Natl Hist Nat Luxemb 31:119-138

Broders HG (2003) Another quantitative measure of bat species activity and sampling intensity considerations for the design of ultrasonic monitoring studies. Acta Chiropter 5:235-241

Brooks RT, Ford WM (2005) Bat activity in a forest landscape of Central Massachusetts. Northeast Nat 12:447-462. doi:10.1656/ 1092-6194(2005)012[0447:BAIAFL]2.0.CO;2

Butler DR, Malanson GP (2005) The geomorphic influences of beaver dams and failures of beaver dams. Geomorphology 71:48-60. doi:10.1016/j.geomorph.2004.08.016

Ciechanowski M, Zajac T, Biłas A, Dunajski R (2007) Spatiotemporal variation in activity of bat species differing in hunting tactics: effects of weather, moonlight, food abundance, and structural clutter. Can J Zool 85:1249-1263. doi:10.1139/Z07-090

Collen P, Gibson RJ (2000) The general ecology of beavers (Castor spp.) as related to their influence on stream ecosystems and riparian habitats, and the subsequent effects on fish-a review. Rev Fish Biol Fish 10:439-461. doi:10.1023/A:1012262217012

Dalbeck L, Lüscher B, Ohlhoff D (2007) Beaver ponds as habitat of amphibian communities in a central European highland. Amphib Reptil 28:493-501. doi:10.1163/156853807782152561

DeBano LF, Heede BH (1987) Enhancement of riparian ecosystems with channel structures. Water Resour Bull 23:463-470. doi:10.1111/j.1752-1688.1987.tb00824.x

Dietz M, Encarnaçào JA, Kalko EKV (2006) Small scale distribution patterns of female and males Daubenton's bats (Myotis daubentonii). Acta Chiropter 8:403-413. doi:10.3161/ 150811006779398528

Downs NC, Racey PA (2006) The use by bats of habitat features in mixed farmland in Scotland. Acta Chiropter 8:169-185. doi: $10.3161 / 150811006777070893$

Ellison LE, Everette AL, Bogan MA (2005) Examining patterns of bat activity in Bandelier national monument, New Mexico, by using walking point transects. Southwest Nat 50:197-208. doi:10.1894/ 0038-4909(2005)050[0197:EPOBAI]2.0.CO;2

Erickson J, West S (2003) Association of bats with local structure and landscape features of forested stands in western Oregon and Washington. Biol Conserv 109:95-102. doi:10.1016/S0006-3207(02)00141-6

Fenton MB, Morris D (1976) Opportunistic feeding by desert bats (Myotis spp.). Can J Zool 54:526-530. doi:10.1139/z76-059

Ford WM, Menzel MA, Rodrigue JL, Menzel JM, Johnson JB (2005) Relating bat species presence to simple habitat measures in a 
central Appalachian forest. Biol Conserv 126:528-539. doi:10.1016/j.biocon.2005.07.003

Francl K, Ford WM, Castleberry SB (2004) Bat activity in Central Appalachian Wetlands. Ga J Sci 62:87-94

Fukui D, Murakami M, Nakano S, Aoi T (2006) Effect of emergent aquatic insects on bat foraging in a riparian forest. J Anim Ecol 75:1252-1258. doi:10.1111/j.1365-2656.2006.01146.x

Grindal SD, Morissette JL, Brigham RM (1999) Concentration of bat activity in riparian habitats over an elevational gradient. Can J Zool 77:972-977. doi:10.1139/cjz-77-6-972

Grover AM, Baldassarre GA (1995) Bird species richness within beaver ponds in south-central New York. Wetlands 15:108-118. doi:10.1007/BF03160664

Gurnell AM (1998) The hydrogeomorphology effects of beaver dambuilding activity. Prog Phys Geogr 22:167-189. doi:10.1177/ 030913339802200202

Haarberg O, Rosell F (2006) Selective foraging on woody plant species by the Eurasian beaver (Castor fiber) Telemark, Norway. J Zool 270:201-208. doi:10.1111/j.1469-7998.2006.00142.x

Halley DJ, Rosell F (2003) Population and distribution of European beavers (Castor fiber). Lutra 46:91-101

Hood GA, Bayley SE (2008) The effects of high ungulate densities on foraging choices by beaver (Castor canadensis) in the mixedwood boreal forest. Can J Zool 86:484-496. doi:10.1139/Z08029

Hood GA, Bayley SE (2009) A comparison of riparian plant community response to herbivory by beavers (Castor canadensis) and ungulates in Canada's boreal mixed-wood forest. For Ecol Manag 259:1979-1989. doi:10.1016/j.foreco.2009.07.052

Jones CG, Lawton JH, Shachak M (1994) Organisms as ecosystem engineers. Oikos 69:373-386

Jones G (1995) Flight performance, echolocation and foraging behaviour in noctule bats Nyctalus noctula. J Zool 237:303312. doi:10.1111/j.1469-7998.1995.tb02764.x

Jones G, Rayner JMV (1988) Flight performance, foraging tactics and echolocation in free-living Daubenton's Bats Myotis daubentonii (Chiroptera: Vespertilionidae). J Zool 215:113-132. doi:10.1111/ j.1469-7998.1988.tb04888.x

Jones G, Rydell J (1994) Foraging strategy and predation risk as factors influencing emergence time in echolocating bats. Philos Trans R Soc B 346:445-455. doi:10.1098/rstb.1994.0161

Kalcounis-Rueppell MC, Payne VH, Huff SR, Boyko AL (2007) Effects of wastewater treatment plant effluent on bat foraging ecology in an urban stream system. Biol Conserv 138:120-130. doi:10.1016/j.biocon.2007.04.009

Kalko EMV (1995) Insect pursuit, prey capture and echolocation in pipistrelle bats (Microchiroptera). Anim Behav 50:861-880. doi:10.1016/0003-3472(95)80090-5

Kaňuch P, Danko Š, Celuch M, Krištín A, Pjenčák P, Matis Š, Šmídt J (2007) Relating bat species presence to habitat features in natural forests of Slovakia (Central Europe). Mamm Biol 73:147-155. doi:10.1016/j.mambio.2006.12.001

Kauffman JB, Beschta RB, Otting N, Lytjen D (1997) An ecological perspective of riparian and stream restoration in the Western United States. Watershed Restor 22:12-24

Kusch J, Weber C, Idelberger S, Koob T (2004) Foraging habitat preferences of bats in relation to food supply and spatial vegetation structures in a western European low mountain range forest. Folia Zool 53:113-128

Lloyd A, Law B, Goldingay R (2006) Bat activity on riparian zones and upper slopes in Australian timber production forests and the effectiveness of riparian buffers. Biol Conserv 129:207-220. doi:10.1016/j.biocon.2005.10.035

Mackey RL, Barclay RMR (1989) The influence of physical clutter and noise on the activity of bats over water. Can J Zool 67:11671170. doi:10.1139/z89-168
Martinsen GD, Driebe EM, Whitham TG (1998) Indirect interactions mediated by changing plant chemistry: beaver browsing benefits beetles. Ecology 79:192-200. doi:10.1890/0012-9658(1998)079 [0192:IIMBCP]2.0.CO;2

McDowell DM, Naiman RJ (1986) Structure and function of a benthic invertebrate stream community as influenced by beaver (Castor canadensis). Oecologia 68:481-489. doi:10.1007/BF00378759

Menzel MA, Carter TC, Ford WM, Chapman BR (2001) Tree-roost characteristics of subadult and female evening bats (Nycticeius humeralis) in the upper coastal plain of South Carolina. Am Midl Nat 145:112-119. doi:10.1674/0003-0031(2001)145[0112: TRCOSA]2.0.CO;2

Menzel JM, Menzel MA, Kilgo JC, Ford WM, Edwards JW, McCracken GF (2005a) Effect of habitat and foraging height on bat activity in the costal plain of South Carolina. J Wildl Manage 69:235-245. doi:10.2193/0022-541X(2005)069<0235: EOHAFH $>2.0 . \mathrm{CO} ; 2$

Menzel JM, Menzel MA, Kilgo JC, Ford WM, Edwards JW (2005b) Bat response to Carolina bays and wetland restoration in the southeastern U.S. coastal plain. Wetlands 25:542-550. doi:10.1672/0277-5212(2005)025[0542:BRTCBA]2.0.CO;2

Metts BS, Lanham JD, Russell KR (2001) Evaluation of herpetofaunal communities on upland streams and beaverimpounded streams in the upper piedmont of South Carolina. Am Midl Nat 145:54-65. doi:10.1674/0003-0031(2001)145 [0054:EOHCOU]2.0.CO;2

Mickevičiené I, Mickevičius E (2001) The importance of various habitat types to bats (Chiroptera: Vespertilionidae) in Lithuania during the summer period. Acta Zool Litu 1:3-14

Nakano S, Murakami M (2001) Reciprocal subsidies: dynamic interdependence between terrestrial and aquatic food webs. PNAS 98:166-170

Nummi P (1989) Simulated effects of the beaver on vegetation, invertebrates and ducks. Ann Zool Fenn 26:43-52

Nummi P (1992) The importance of beaver ponds to waterfowl broods: an experiment and natural tests. Ann Zool Fenn 29:47-55

Nummi P, Poysa H (1997) Population and community level responses in Anas-species to patch disturbance caused by an ecosystem engineer, the beaver. Ecography 20:580-584. doi:10.1111/j.16000587.1997.tb00426.x

Paine RT (1969) The Pisaster-Tegula interaction: prey patches, predator food preference, and intertidal community structure. Ecology 50:950-961. doi:10.2307/1936888

Patriquin KJ, Barclay RMR (2003) Foraging by bats in cleared, thinned and unharvested boreal forest. J Appl Ecol 40:646-657. doi:10.1644/06-MAMM-A-254R1.1

Popescu VD, Gibbs JP (2009) Interactions between climate, beaver activity, and pond occupancy by the cold-adapted mink frog in New York State, USA. Biol Conserv 142:2059-2068. doi:10.1016/j.biocon.2009.04.001

Rachwald A (1992) Habitat preference and activity of the noctule bat Nyctalus noctula in the Białowieża Primeval Forest. Acta Theriol 37:413-422

Ray AM, Rebertus AJ, Ray HL (2001) Macrophyte succession in Minnesota beaver ponds. Can J Bot 79:487-499. doi:10.1139/ cjb-79-4-487

Roni P, Beechie TJ, Bilby RE, Leonetti FE, Pollock MM, Pess GR (2002) A review of stream restoration techniques and a hierarchical strategy for prioritizing restoration in Pacific Northwest watersheds. N Am J Fish Manage 22:1-20. doi:10.1577/ 1548-8675(2002)022<0001:AROSRT >2.0.CO;2

Rosell F, Bozsér O, Collen P, Parker H (2005) Ecological impact of beavers Castor fiber and Castor canadensis and their ability to modify ecosystems. Mamm Rev 35:248-276. doi:10.1111/ j.1365-2907.2005.00067.x 
Russ JM, Montgomery WI (2002) Habitat associations of bats in Northern Ireland: implications for conservation. Biol Conserv 108:49-58. doi:10.1016/S0006-3207(02)00089-7

Russell KR, Moorman CE, Edwards JK, Metts BS, Guynn DC (1999) Amphibian and reptile communities associated with beaver (Castor canadensis) ponds and unimpounded streams in the piedmont of South Carolina. J Freshw Ecol 14:149-158

Rydell J, Bushby A, Cosgrove CC, Racey PA (1994) Habitat use by bats along rivers in north east Scotland. Folia Zool 43: 417-424

Rydell J, Miller LA, Jensen MF (1999) Echolocation constraints of Daubenton's bat foraging over water. Funct Ecol 13:247-255. doi:10.1046/j.1365-2435.1999.00304.x

Rydell J, Petersons G (1998) The diet of the noctule bat Nyctalus noctula in Latvia. Z Säugetierkd 63:79-83

Sachanowicz K, Ciechanowski M, Piksa K (2006) Distribution patterns, species richness and status of bats in Poland. Vespertilio 9-10:151-173

Siemers B, Schnitzler HU (2004) Echolocation signals reflect niche differentiation in five sympatric congeneric bat species. Nature 429:657-661. doi:10.1038/nature02547

Sidorovich VE, Jędrzejewska B, Jędrzejewski W (1996) Winter distribution and abundance of mustelids and beavers in the river valleys of Bialowieża Primeval Forest. Acta Theriol 41: 155-179

Siemers BM, Baur E, Schnitzler HU (2005) Acoustic mirror effect increases prey detection distance in trawling bats. Naturwissenschaften 92:272-276. doi:10.1007/s00114-005-0622-4

Stevens CE, Paszkowski CA, Lee Foote A (2007) Beaver (Castor canadensis) as a surrogate species for conserving anuran amphibians on boreal streams in Alberta, Canada. Biol Conserv 134:1-13. doi:10.1016/j.biocon.2006.07.017
Todd VLG, Waters DA (2007) Strategy-switching in the gaffing bat. J Zool 273:106-113. doi:10.1111/j.1469-7998.2007.00306.x

Vaughan N (1997) The diets of British bats (Chiroptera). Mamm Rev 27:77-94. doi:10.1111/j.1365-2907.1997.tb00373.x

Vaughan N, Jones G, Harris S (1996) Effects of sewage effluent on the activity of bats (Chiroptera: Vespertilionidae) foraging along rivers. Biol Conserv 78:337-343. doi:10.1016/S0006-3207(96)00009-2

Vaughan N, Jones G, Harris S (1997a) Habitat use by bats (Chiroptera) assessed by means of a broad-band acoustic method. J Appl Ecol 34:716-730

Vaughan N, Jones G, Harris S (1997b) Identification of British bat species by multivariate analysis of echolocation call parameters. Bioacoustics 7:189-207

Walsh AL, Harris S (1996) Foraging habitat preferences of vespertilionid bats in Britain. J Appl Ecol 33:508-518

Warren RD, Waters DA, Altringham JD, Bullock DJ (2000) The distribution of Daubenton's bats (Myotis daubentonii) and pipistrelle bats (Pipistrellus pipistrellus) (Vespertilionidae) in relation to small-scale variation in riverine habitat. Biol Conserv 92:85-91. doi:10.1016/S0006-3207(99)00062-2

Weiskittel AR, Hix DM (2003) Canopy gap characteristics of an oakbeech-mapple old-growth forest in Northeastern Ohio. Ohio J Sci 103:111-115

Worrall JJ, Lee TD, Harrington TC (2005) Forest dynamics and agents that initiate and expand canopy gaps in Picea-Abies forests of Crawford Notch, New Hampshire, USA. J Ecol 93:178-190. doi:10.1111/j.1365-2745.2004.00937.x

Zar JH (1996) Biostatistical analysis. Prentice-Hall International, Inc., Upper Saddle River, New Jersey

Zwolicki A (2005) European Beaver Castor fiber-a keystone species for the river valley ecosystems. Ecol Questions 6:106-109 